carpal bones of the second and third fingers were soft and pulpy, involved in, and firmly attached to, the diseased growths, he determiued to remove these two bones, wilh the fingers, at the carpal articulation. This was speedily effected; the whole mass was removed, and the palm was left entire. There was a good deal of hæmorrhage; several vessels were tied.

6. The wound is granulating kindly.

13. Has been going on well since the last report, and he will have a comparatively useful hand.

Mr. Liston said, that the above case was a very puzzling one. He had been, by the previous history, led to suppose that the disease was confined to the soft parts. The students, however, had seen what took place in the operation, and that the disease was not only seated in the soft parts, but had extended also to the bones, which were quite soft, and had thrown up spicula into the tumour. It was not improbable that the mischief had originally sprung from the medullary canal of the middle metacarpal bone. He thought at first, on discovering this, that nothing but the removing the hand would avail; but he was enabled, by acting on the spar of the moment, and performing a difficult operation, to save the best part of the hand. $\mathrm{He}$ had, as they saw, removed the metacarpal bones of the middle aud ring finger, which was certainly much better for the patient than losing his entire hand. Operations of this description were generally required after gun-shot wounds, of injuries from machinery. The hand was not to be removed, though much of it might be involved in disease or perfectly smashed; it was the duty of the surgeon to save as much of it as possible, if it were only the first, or little finger, it should be saved; but where the thumb with a finger to meet it could be preserved, the patient had, to a certain extent, a very useful member, better than could be supplied by any kind of machinery. Surgeons were not warranted in renoving tbe hand in such a case as that (showing a drawing), in which there was a gun-shot wound involving only the first finger; nor were they to operate for removal of the hand even though shot had passed through the middle of it. It was only when mortification had set in that amputation in such cases was a justifiable proceeding. The same rule was also to be observed in injuries of the foot, and an instructive case of this $k$ ind had been brought into the hospital, just as the operation in the present case was concluded.

THE proportion of still-born children, is about 1 to 22 . The proportion is much larger in towns than in rural districts, which M. Quetelet is much inclined to attribute to tight lacing. Still-born births occur more frequently in winter than summer.

\section{THE TEETH A TEST OF AGE.}

\section{To the Editor of Tine Lancer.}

Srn:-I have to request the favoul of the insertion in THE LANCET of the following practical observations on the manner ir which the examination of the teeth is to bt conducted, with a view to determine the ag of children, more particularly with referenc to their qualification for factory labour They have been drawn up at the suggestion of Messrs. Horner and Saunders, two of th inspectors of factories, who have, to a con siderable extent, adopted in their district the test, into the value of which $I$ instituter an inquiry in the early part of the last year; and have assured me that it has been at tended with the most satisfactory results I have the honour to be, Sir, your obedien servant,

\section{6, Argyll-street, June 16, 1838.}

The following observations, which are in tended as

\section{Brief Hints to the Cerlifying Surgeons,}

are founded upon the results of the carefu examination of upwards of 2000 cases, an may, therefore, be relied on with some de gree of confidence.

Age having been pronounced by th Crown lawyers, whose opinion has bee sought upon the subject, to be the primar. object of inquiry, in granting a certificate 0 qualification for factory labour, and thi development of the teeth having been show to be the best criterion of age, to be ob tained from the physical characters, th question presents itself, what are the appear ances of the mouth at the particular age: contemplated in the Factories Regulatiol Act?

The Act has provided that no child shal be employed in cotton, woollen, and fla: mills under nine years of age, and that $n$ child under thirteen years of age shall wort in those mills more than nine hours in an! one day, or more than 48 hours in any oui week. These, then, are the ages to which the attention of the certifying surgeon is t be directed, and the following. would ap pear to be the developments proper to thos periods :-

* See "The Teeth a Test of Age, consi dered, with reference to the Factury Chil dren," by Edwin Saunders, Lecturer on th Anatomy and Diseases of the Teeth, \&c. \&i Renshaw, 356, Straud. 


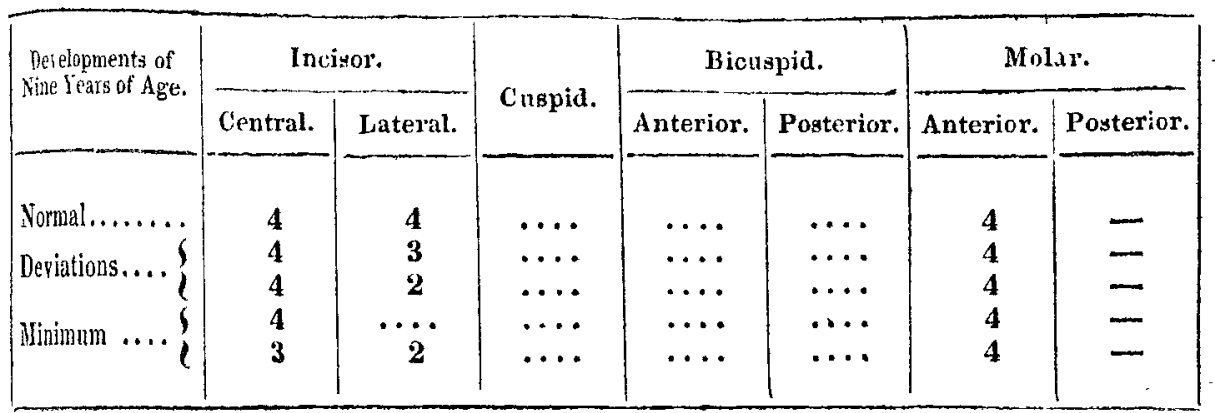

It need scarcely be observed, that in the cases, however, which should be regarded foregoing table the second or permanent as the minimum developments of this age, teth only are regarded. It may frequently occur but rarely (in about the proportion of bappen that these present themselves in an 7 per cent.), so that unless a child exhibit nnusual position, the corresponding teeth of unequivocal!y the general aspect and the first set being still retained. This, $\mid$ strength it cannot be considered as being of boferer, will not affect the examination, nine years of age. 'Thus, then, the examisince it is not the absolute number of teeth nation of the teeth at the age of nine years coutained in the mouth, but only the num - is exceedingly simple, virtually resolving ber of the second set, which may be in a itself, indeed, into the observation of the more or less advanced stage of develop- eight teeth situated in the anterior part of ment, on which reliance is to be placed. In the mouth ; the incisors, - for the molar the fist line of the table the full develop- teeth, although they are recorded in tho ments of the ninth year are recorded. In table, need scarcely be regarded,-being the lis case the four incisor teeth of the per- earliest of the permanent teeth which are manent set in each row have succeeded to developed, and generally making their apthe places of those of the first, and from the pearance between the sixth and serenth consentaneous growth and expansion of the year.

maxillary bones, no retardation or mal-posi- The developments at thirteen years of tion will he observed. From this, how- age appear sumewhat more complex; the ever, although observation has shown it to examination at this age, however, will be be of more frequent occurrence than any found to be equally simple, for it fortuother, there are many deviations. The first nately happens that the ages contemplated of these is where the lateral incisor, from in the Factories Regulation $\Lambda$ ct, are those deficient derelopment of the maxillary bone, which of all others are best characterised by is crorded and pressed upon, so as to pre- the developments of the teeth, and are best vent its eruption from the gum. This may adapted for examination. Both epochs are occul in either the upper or under row, or well marked by the appearance of important butli; in either case it should be reckoned teeth; the first by the development of the as present, and its absence attributed to incisor and first molar teeth, the second by some mechanical obstruction retarding its that of the cuspid and second molar; the progress, provided its fellow be freely deve- intervening period being occupied in the loped. Occasionally, but rarely, the lateral development of the bicuspid teeth, which incisors are allogether wanting, and still are suliject to much greater irregularity in mione seldom one of the central incisors (in the time and order of their eruption, the age the upper row) is absent. In the latter is of consequence much less distinctly indirase, provided the lateral incisors should cated. At thirteen years of age the followhave nade their appearance, the absent lowing teeth will have made their appeartoold should be reckoned as present. These ance :-

\begin{tabular}{|c|c|c|c|c|c|c|c|}
\hline \multirow{2}{*}{$\begin{array}{l}\text { Derelopments } \\
\text { of Thisteen Ieurs } \\
\text { of Age. }\end{array}$} & \multicolumn{2}{|c|}{ Incisor. } & \multirow{2}{*}{ Cuspid. } & \multicolumn{2}{|c|}{ Bicuspid. } & \multicolumn{2}{|c|}{ Molar. } \\
\hline & Central. & Iateral. & & Anterior. & Posterior. & Anterior. & Posterior. \\
\hline Nornal........ & 4 & 4 & 4 & 4 & 4 & 4 & 4 \\
\hline Deriations.... & $\begin{array}{l}4 \\
4\end{array}$ & $\begin{array}{l}4 \\
4\end{array}$ & $\ddot{1}$ & $\begin{array}{l}4 \\
4\end{array}$ & $\begin{array}{l}2 \\
1\end{array}$ & $\begin{array}{l}4 \\
4\end{array}$ & $\begin{array}{l}3 \\
2\end{array}$ \\
\hline Hinimum...... & 4 & 4 & 4 & 4 & $\mathbf{3}$ & 4 & - \\
\hline
\end{tabular}


The most important teeth to be observed at this period are the cuspid, or canine, and the second molar, the seventh tooth from the centre of the mouth. The intermediate class, the bicuspid, when the process of dentition proceeds normally, will have made their apnearance, but they are subject to much variation, and need not be particularly regarded. The more frequent deviations will be found to occur in the second molar teeth, one or more, and in some instances the whole of which will not have made their appearance.

In these cases, if the cuspid teeth be freely developed, and the child present the ordinary physical appearances belonging to the age, it may be considered as having attained its thirteenth year, because occasionally, though rarely (such cases bearing a proportion of scarcely more than 2 per cent.), this deviation is encountered. More frequently one or more of the second nolar teeth may be observed just emerging from the gums, but in comparatively few cases will the whole be found fully developed, an appearance which belongs to the fourteenth year. More rarely still the cuspid teeth will be deficient; in these cases which are, however, seldom encountered, the decision must depend upon the degree of developinent of the second molar teeth, if these are present, as the period of their eruption is subsequent to that of the cuspid teeth, and provided the physical appearances coincide, the child may be presumed to have attained $i$ ts thirteenth year. The minimum developments of this age are where one of the cuspid only, and two of the second molar teeth, are present, and vice versa, or where the whole of the second molar teeth are absent.

Thus, then, the examination at this period is sufficiently simple, the observation being confined to the cuspid and second molar teeth. The former being large prominent teeth, and situated at the angle of the lips, are easily recognised, and the latter may be distinguished with the utmost facility from the eircumstance of their being the seventh teeth from the centre of the mouth.

The question, howerer, is often asked what are the characteristic differences between the teeth of the first and those of the second set? It cannot be denied that this is a subject of the first importance, since the most serions and irreparable mischiế may arise from malpractice resulting from the want of a distinct and definite diagnosis.

The characteristic differences between the first and second set of teeth are of three kinds, -

First. Difference of size.

Second. Difference of form and configuration.

Third. The degree of abrasion which they have suffered.

The first and most obvious distinction be- tween the temporary and permanent teeth $i$ the difference of size, the former being littl more than half that of the latter. This ma be well observed in cases where little ex pansion of the maxillary bones has take place at the time of shedding. Normally or where cousentaneous growth has pre ceeded in the containing and containe parts, where the jaw has become develope it due proportion, a considerable inters: may be observed between the temporap teeth at this period; the teeth will no longe be in apposition, but separated more or les from each other, so that when their succe sors make their appearance only the corre sponding teeth of the temporary set are dis placed, the greater width of the new teet being compensated by the intervenin space ; where, however, the growth of th jaw and the development of the teeth har not been consentaneous, the new tooth be ing impeded in its progress, will make it appearance in an unusual position, requi ing the additional removal of neighbouin teeth. Thus, to afford sufficient space $f t$ the central incisor of the permanent set, will be frequently necessary to remove only the corresponding tooth of the first se but also the lateral incisor; in ordinat cases, however, no such interference will necessary, or even justifiable; but whethe the removal of the lateral incisor be nece sary or not, a considerable difference of sir will generally be observable betwean it teeth of the first and those of the second 8 in favour of the latter. This, however, not invariably the case; occasionally cast present themselves in which little diferer in this respect exists, and from their bein discoloured and disguised by an accumal tion of tartar, it may be exceedingly dif cult, relying solely upon the difference. size, to determine to which get they belons An additional characteristic must then sought, and this will readily presentitself $i$

Second, The differences of form and col figuration. The teeth most likcly to be wi taken as belonging to the frst set, are th first permanent molares, which, except h an experienced eye, are sometimes with di ficulty distinguished from the second ten porary teeth of that class ; these, indeet make their appearance in a situation post rior to the temporary molares, and themtior being superadded to the first set, and thr constituting the sixth tooth from the centu of the mouth, may in this manner be ditit guished. But it frequently happens the one or more of the molar teeth of the fir set may have been removed, and in sne cases if enumeration be solely relied on, th judgment will he erroneous, or at least u certain. The difference of gize will also $t$ a feeble auxiliary, for although the fir molar tooth of the permanent set is th largest of all the teeth, yet the difference size between it and the second temporar 
molar will affurd but little confidence in determining its character. In such cases the form and configuration become a most valuable criterion, and one of the most striking characteristic distinctions of this kind is the abrut termination of the enamel on the neck of the tooth. On the permanent teeth the enamel, becoming gradually thinner as it ascends, terminates in an almost imperceptible lime, and the exact boundary can searcely be traced where this beautifnl structure ceases to invest the bone of the looth. The temporary teeth, however, present a very different appearance; on them the enamel, instead of being shaded off, as it were, as it approaches that portion of the tooth which is embraced by the gum, and which is termed the neck, continues of a uniform thickness, or nearly so, and ceases abruptly, forming a protuberant ridge immediately below the gum. There are other differences of form which will suggest themselves to those who are familiar with the subject; but there is probably none which is so well defined and so constant as that which has just been pointed out. This distibction may be observed equally in all the different classes of teeth, and is generally well marked in the incisors. Whatever may be the variations in the breadth of these teen there is uniformly a great diffe!ence in the length, and therefore in cases in which the permanent incisors are reveloped only to the same extent as the temporary teeth of that class, while this ridge, marking the termination of the enamel, may be observed on the latter, a continuous eveu surface will be presented by the former, the Thole of the crown of the tooth (the portions corered with enamel) not having emerged from the gum. Shonld the crown, however, have become fully developed, the difference maxy still be observed in so marked a manner on passing the finger nail over the tooth uprards, from the cutting edge, as to prednde donbt, or the possibility of mistake.

Another obvious and striking aistincion, bowever, is to be found in

Third, The degree of abrasion which the teeth have suffered. This is more strikingly exhibited in the teeth situated in the anterion part of the mouth, but it belongs in a greater or less degree to all. It is obvions that teeth which have been fulfilling their fubctions for a period of from six to seven years, must have undergnne some alteration, in form and appearauce, from abrasion. The cutting edge of the newly formed tooth will be completely invested with enamel, and will present a serrated or notched appearance, which in a short time becomes obliterated and worn down; at the lime of shedding, however, the enamel has been en. tirely removed by abrasion from the edge, which appears thick and broad, with a dark line of boge included between the two layers of enamel investing the anterior and posterior surface of the tooth. Such an edge will be readily distinguished from the round, tapering, pearly edge of the newly. formed tooth. A similar deterioration occurs in the cuspid teeth, the points of which become worn down so that they may be still more readily distinguished than the incisn's. The attrition of mastication does not, howerer, appear to produce an equal deterioration in the form of the crowns of the molar teeth, so that with respect to these teeth the most obvious and certain diagnosis will be found in the abrupt termination of the enamel at the neck.

Such are the most striking and palpable distinctions between the first and second sets of teeth ; in addition to which may be mentioned, as an auxiliary, the relative position which they occupy in the mouth. Thus the temporary set, consisting of twenty in number, the first molar tooth of that set will be the fourth from the centre of the mouth; the second will in like manner be the fifth. This, then, will constitute the last of the temporary set, and will complete the number of twenty, which the child pos. sesses up to the age of six or seven years, when a new molar tooth may be seen emerging from the gum, without displacing any of the temporary teeth, immediately belind the last molar of that set. This, which is the first molar tooth of the second set, will be the sixth from the centre of the mouth : from this period, therefore, to the age of thirtees or fourteen years (when the second permaneut molar becomes developed), the child possesses twenty-four teeth. With respect to the diagnosis between the first and the second molar teeth of the permanent set, with which, when the examination is made with the view of arriving at a knowledge of age, it is of the utmost importance to be familiar, it has been alieady observ. ed, that its distance from the centre of the month will gencrally determine the question. It may happen, however, that the first permanent molar bas been removed, and the second has advanced nearly to the place which it occupied, and is in a forward state of development. The difference of form must, in such cases, be relied on. In the , upper row the second may be distinguished fiom the first molar tooth, by its presenting on its inner, or palatine side, a round protuberant surface, and by its being marked on the crown by a triangular depression, while the first molar is of a square, or rather of a rhomboidal figure, divided by a crucifor'm furrow into four or tive tubercles. In the lower row these distinctions do not obtain, and the difrerence of form between them is less strongly marked. As in the upper row, however, the first molar is larger than the second, and generally has the appearance of being divided into four prominences, with a small wedge driven into the external half of the transverse division. The second 
is simply divided into four protuberances by a crucial line, or depression.

With these simple and obvions distinctions, with which any one may soon render himself familiar by little practical appli. cation, almost the possibility of error will be precluded in the prosecution of this interesting and important subject.

The following is the result of an examination of the accuracy and value of the test, made Feb. 10, 1838, in the London Orphan Asylum, at Clapton:-

The total number of children examined was 307 ; of these there were 36 of nine years of age, and 48 of thirteen years of age. Of the former 28 were boys and 8 girls; of the latter 39 were boys and 9 girls. Of the 36 children of nine years of age, 30 would have been passed as being fully nine years of age, on an examination of their teeth, and 6 rejected. The real age of one of these was doubtful, and 3 would have passed by their height and general appearance. Of the 48 of thirteen years of age, 42 would have yassed by their dental developments; 6 would have been rejected. Fire of these were more than 4 feet $3 \frac{1}{2}$ inches in height, and the other, thongh short, had the general appearance of thirteen years of age, and was muscular. There were 5 girls, said to be under twelve years of age, who had the dental development of thirteen years; 2 of these were subsequently found to be nearly 13 , and there is a possibility of error in the actual age of the remaining 3 . There were 15 boys between $1 f_{2}$ and 12 years old, who presented the dental developments of 13 years, but there were 20 more whose developments were regular. The variations in height were very great, ranging in the 30 of nine years, who pregented normal dental developments, from 3 feet 7 inches to 4 feet 1 inch.

\section{TREATMENT OF SMALL-POX.}

\section{To the Editor of TuE LANCET.}

Sir:-May I beg the favour, through the medium of your excellent Journal, to make further report of the successful progress of a practice which $I$ advocated in a contempo. rary journal in 1836 , and which practice $I$ am led to believe, originated with myself.* I am, Sir, your very obedient servant,

\section{JOHN LANGILEY.}

\section{6, Tottenhain-street,} Jane 15, 1838.

* The practice of opening; small-pox pustules has lomg been employed by M. Serres, of La Pitie. It was also extensively tried in some of the military hospitals of this country about fifteen years afo.-. FD. L.
At the present time, when I regret to ob. serve in this district, that that baneful dis. ease, small-pox, has been and is still existing to a considerable extent, any mode of practice which has for its object and effect the ameliodation of suffering, \&c., ought to be freely promulgated. Since my publication of the following mode of practice, rery many cases of small-pox have fallen under my treatment, and of those in which the pustules have by puncture and incision been evacuated, I have every reason to be satis. fied that the desirable objects above alluded to have been invariably attained. In almost every case of small-pox where, from the malignity of its character, height of attendant inflammatory fever, and confluent nature of eruption, serious consequences are to be apprehended, upon the pustules acquiring a full and prominent vesicular character, before the lymph assumes its purulent appear. ance, I puncture with a lancet the most depending part of the inferior edge of the pustule, thereby leaving a perfect superficial covering of cuticle, obviating in a great degree the tendency to irritation resulting from the ingress of atmospheric air into the col. lapsed cist, the superjacent cuticle falling as a plaster upon the secreting surface. The expression of relief afforded to the sifferer by this operation is most grateful, and may be somewhat adequately estimated by those who have experienced the comfort of hav. ing the contents of a whitlow evacuated. The desquamating process is not only facilitated, but greatly expedited, as in the course of three or four days, yon have an extensive desquamation, occurring almost simultaneously over the whole surface, leaving discolouration, but seldom any depressions; and in cases where, for the sake of experiment, I have thus proceeded with one superior extremity, and neglected the other, the difference of result has been most manifest. The removal of the distressing tension, pervading so extensive a surface, and pressing upon such sensitive and irritable tissues, cannot fail to give the rationale of the relief afforded, and also the fair pre. sumption, that the cerebral irritation and consequent fever resulting from such a painful condition, must be greatly modified, if not altogether obviated, independently of removing from the inflamed and abraded surfaces an immense quantity of morbifin secretion, the reabsorption of which, to a certain extent, may be reasonably inferred. If, from a prejudice, which oft ignorantly prevails, of interfering with the natural course of naturally incidental diseases, certain persons might not grant the propriety of opening all the cysts (which, by-the-by, is no trifling task) surely they will make trial of the practice upon those parts, the preservation of which is so desirable. 